\title{
Influence of human chorionic gonadotrophin during ovarian stimulation: an overview
}

\author{
Johan Smitz ${ }^{1}$ and Peter Platteau ${ }^{2^{*}}$ (i)
}

\begin{abstract}
It is widely known that luteinising hormone $(\mathrm{LH})$ and human chorionic gonadotrophin $(\mathrm{hCG})$ are integral in the female reproductive lifecycle. Due to the common binding site and similarity in molecular structure, they were previously thought to have overlapping roles. However, with the development of both purified urinary-derived and recombinant gonadotrophins, the individual characteristics of these molecules have begun to be defined. There is evidence to suggest that LH and hCG preferentially activate different signalling cascades and display different receptor-binding kinetics. The data generated on the two molecules have led to an improved understanding of their distinct physiological functions, resulting in a debate among clinicians regarding the most beneficial use of LH- and hCG-containing products for ovarian stimulation (OS) in assisted reproductive technologies (ARTs). Over the past few decades, a number of trials have generated data supporting the use of hCG for OS in ART. Indeed, the data indicated that hCG plays an important role in folliculogenesis, leads to improved endometrial receptivity and is associated with a higher quality of embryos, while presenting a favourable safety profile. These observations support the increased use of hCG as a method to provide LH bioactivity during OS. This review summarises the molecular and functional differences between hCG and LH, and provides an overview of the clinical trial data surrounding the use of products for OS that contain LH bioactivity, examining their individual effect on outcomes such as endometrial receptivity, oocyte yield and embryo quality, as well as key pregnancy outcomes.
\end{abstract}

Keywords: Luteinising hormone, Human chorionic gonadotrophin, Human menopausal gonadotrophin, Assisted reproductive technology, Ovarian stimulation

\section{Background}

Human chorionic gonadotrophin (hCG) and luteinising hormone (LH) are two hormones of the female reproductive system that, despite their similar structures, common receptor and overlapping physiological roles, have distinct differences in terms of their bioactivity and physiological function [1, 2]. Follicular growth and development are conventionally associated with LH, which enhances ovarian steroidogenesis through the two-cell,

\footnotetext{
* Correspondence: peterplatteau@bivf.eu

${ }^{2}$ Centre for Reproductive Medicine, Universitair Ziekenhuis Brussel, Vrije Universiteit Brussel, Brussels, Belgium

Full list of author information is available at the end of the article
}

two-gonadotrophin' theory [3-5]. In contrast, hCG has mostly been identified as the 'pregnancy hormone' due to its role in embryo implantation and pregnancy maintenance $[6,7]$. However, hCG expression has also been confirmed in non-pregnant women of reproductive age, where it is thought to play a role during the normal menstrual cycle, as well as in men and post-menopausal women $[2,8]$. In addition, a number of trials carried out over the past decade have described data supporting the use of hCG for ovarian stimulation (OS) in assisted reproductive technologies (ARTs), suggesting a role in folliculogenesis [2, 8-12]. Post-hoc analyses of these data suggest improved endometrial receptivity and embryo 
quality during OS cycles with hCG-containing products versus those without [11-14]. These observations have added strength to the increased use of hCG to provide $\mathrm{LH}$ activity during OS in ART $[11,12]$. However, an increased understanding of the key differences between LH and hCG has revealed significant variance in their physiological functions, resulting in a debate among clinicians regarding the most beneficial use of $\mathrm{LH}-$ and hCG-containing products for OS [1].

This review will discuss the differences between hCG and $\mathrm{LH}$ at the molecular and functional levels, explore the evolution of their pharmacological use in ART, before examining the clinical trial data surrounding the use of products that contain LH bioactivity derived from LH or hCG in OS.

\section{Biological differences between hCG and LH Molecular structure}

hCG and LH are structurally similar molecules; they both belong to a family of heterodimeric glycoprotein hormones $[1,6]$ and consist of highly glycosylated, noncovalently linked alfa and beta subunits (Fig. 1). The alfa subunit, consisting of 92 amino acids, is common not only in hCG and LH but also in FSH and thyroidstimulating hormone $[1,6,16]$. The beta subunits differ in length and confer structural individuality, as well as specificity of physiological activity to each hormone. The main difference between beta subunits of hCG and LH lies with the 24-amino-acid carboxy-terminal peptide (CTP) extension sequence, which contains four O-linked carbohydrate side chains (Fig. 1) [17, 18]. The LH precursor undergoes cleavage of the CTP sequence during protein synthesis to become a protein that is 121 amino acids in length $[1,17,18]$. In addition, the beta subunits of hCG and LH have differing levels of post-translational glycosylation, which has an important impact on the structural conformation of the molecule, as well as its bioactivity [1, 19-21].

Further differences between hCG and LH are displayed in vivo through the existence of multiple isoforms of each molecule. Owing to variation in the content of terminal sialic acid, LH and hCG display extensive charge heterogeneity depending on the isoform. The isoforms of $\mathrm{LH}$ have an isoelectric point (pI) ranging from $<4.0$ to $>7.2$, whereas the pI of hCG ranges from 3 to 7 due to the higher acidity of some hCG isoforms [22, 23]. The composition of $\mathrm{LH}$ isoforms appears to vary throughout the reproductive lifecycle, with younger women presenting isoforms with a shorter half-life and decreased potency. The different hCG isoforms have been previously reviewed in detail $[1,8,18,24-28]$. The individual isoforms of hCG and LH exhibit different biological functions, which suggests that there may be a unique role for each isoform that could have functional significance [1].

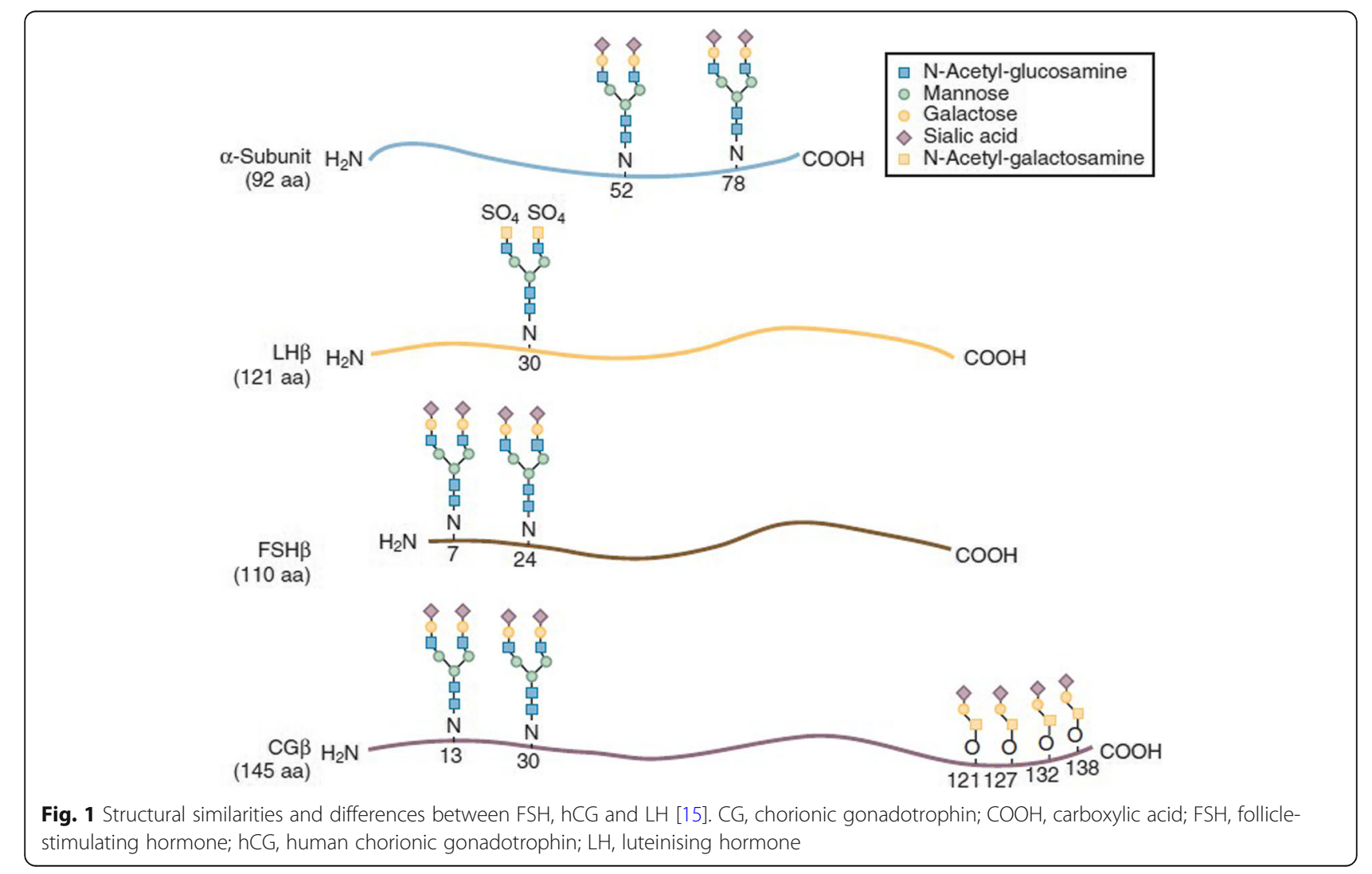




\section{Physiological role in vivo}

The unique presence of the CTP extension confers hCG a markedly increased half-life in comparison to LH (approximately $24-34 \mathrm{~h}$ vs approximately $30-60 \mathrm{~min}$, respectively [29, 30]). The specific effect of CTP has previously been demonstrated in pharmacokinetics studies investigating the addition of the CTP extension to the wild-type recombinant FSH beta ( $\mathrm{rFSH}$ beta) molecule. FSH is commonly used in ART protocols for OS, but due to the relatively rapid clearance of the wild-type molecule, daily administration is required. Investigators aimed to extend the clearance of $\mathrm{rFSH}$ beta in order to reduce the number of injections required during ART procedures. To achieve this, a chimeric $\mathrm{rFSH}-\mathrm{CTP}$ was created by fusing wild-type rFSH beta with a CTP that has an identical amino-acid sequence to the CTP found on hCG [31]. The resulting rFSH-CTP was then tested in pituitary-suppressed females, resulting in a mean elimination half-life of between 60 and $75 \mathrm{~h}$, which is approximately double that of $\mathrm{rFSH}$ beta $[32,33]$. When relating these study outcomes to hCG and LH, as both molecules have a common structure apart from the CTP extension, it can be reasoned that hCG is simply a longer-acting version of $\mathrm{LH}$ and could be thought of as "LH-CTP".

The CTP extension also confers other physiological differences between hCG and $\mathrm{LH}$, in addition to their half-lives. The bioactivities of endogenous hCG and LH are mediated through binding to a common receptor and triggering of specific signalling cascades (Fig. 2) [34, 35]. hCG and LH both bind to the LH/choriogonadotrophin receptor (LH/CGR), a G-protein-coupled receptor consisting of a large, extracellular ligand-binding domain connected to a transmembrane domain via a hinge region $[6,19,36]$. The extracellular domain also has a number of leucine-rich repeats, to which hCG and LH bind in distinct regions with strong affinity and high specificity $[19,36]$. The LH/CGR differentiates between LH and hCG binding through its hinge region, which mediates structural and spatial rearrangements in the receptor by transmitting the ligand-induced extracellular conformational change to the transmembrane region, triggering the activation of complex intracellular pathways $[19,30,34]$. Receptor-activated intracellular pathways include the cyclic adenosine monophosphate (cAMP)/protein kinase A pathway, which results in steroidogenesis and increased progesterone synthesis, and the $\beta$-arrestin and extracellular signal-regulated kinase $1 / 2($ ERK1/2)/protein kinase B (AKT) pathway, which induces proliferative and anti-apoptotic pathways [30]. However, the relative potency of the activation of each pathway is dependent on the ligand [30, 37].

A number of in vitro studies have demonstrated the differences in intracellular responses between LH and

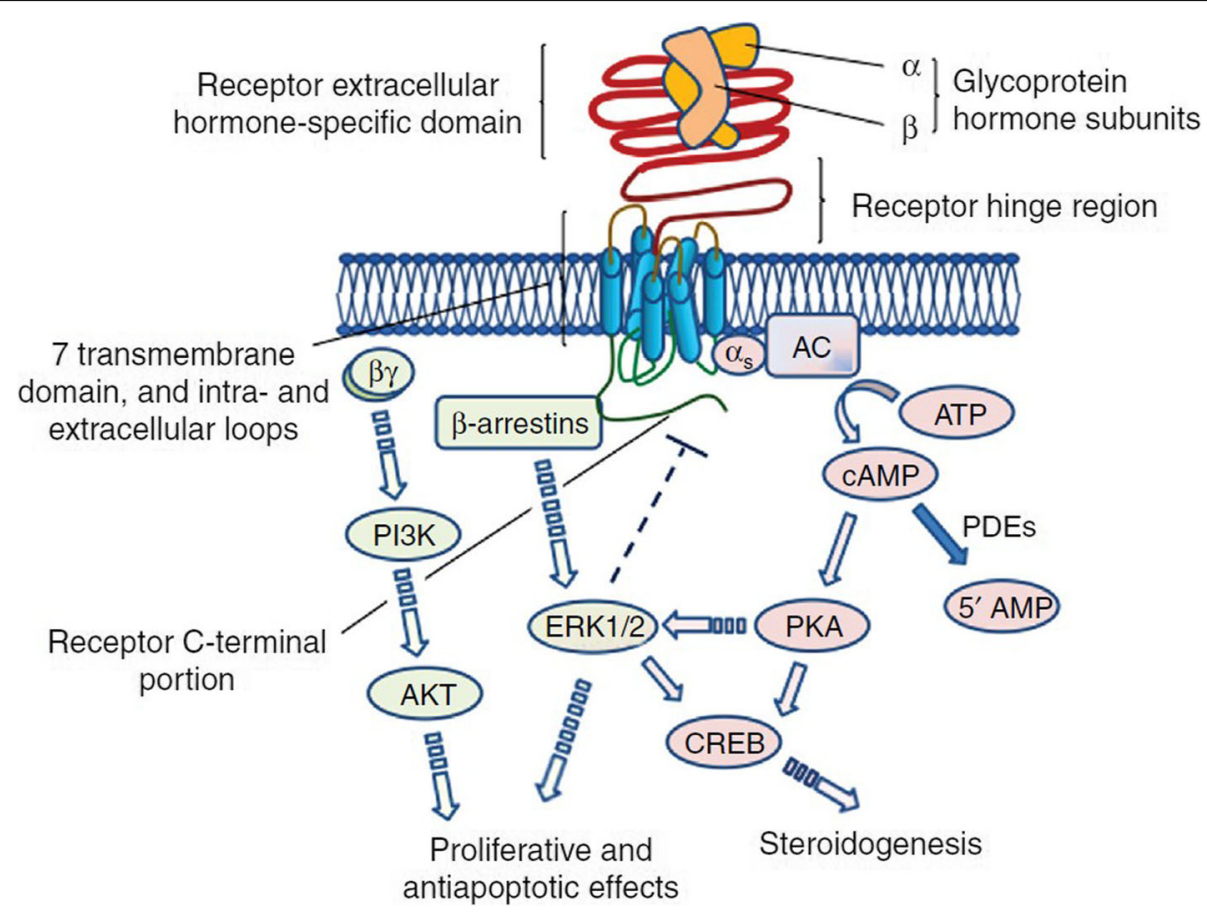

Fig. 2 hCG- and LH-induced signalling cascades via LH/CGR [19]. AC, adenylyl cyclase enzyme; AKT, protein kinase B; ATP, adenosine triphosphate; CAMP, cyclic adenosine monophosphate; CREB, CAMP response element-binding protein; ERK1/2, extracellular regulated kinases 1 and 2; hCG, human chorionic gonadotrophin; LH, luteinising hormone; LH/CGR, luteinising hormone/choriogonadotrophin receptor; PDE, phosphodiesterase enzyme; PI3K, phosphoinositide 3-kinases; PKA, protein kinase A 
hCG via LH/CGR. These studies indicate that LH binding results in a more potent activation of the proliferative and anti-apoptotic ERK1/2 and AKT pathways, whereas hCG has a higher potency for activation of the steroidogenic cAMP pathways [37-39]. In addition, there is evidence to suggest that steroid hormone production differs between hCG and LH. Whereas LH and hCG both fully promote testosterone production, LH only partially stimulates progesterone production, with approximately half the potency of hCG [39].

In keeping with the influence of the CTP component on the half-life of hCG, an in vitro gonadotrophin kinetic binding study using rat LH/CGR revealed that, although hCG and LH have a similar association rate to the receptor $\left(3.4 \times 10^{8}\right.$ and $4.0 \times 10^{8} \mathrm{M}^{-1} \mathrm{~min}^{-1}$ for hCG and human luteinising hormone $[\mathrm{hLH}]$, respectively), hCG displays a markedly longer dissociation rate in contrast to $\mathrm{LH}$ ( $25 \mathrm{~h}$ vs $9.2 \mathrm{~h}$, respectively, measured via the half-times of the bound ligands) [40]. This indicates that hCG interacts with the rat LH/CGR for an increased duration of time; whether these findings translate to hCG displaying a higher binding affinity to the LH/CGR in humans is still to be determined. A recent study investigating the reversibility of hCG or hLH stimulation of mouse Leydig tumour cells found hLH to have a faster rate of dissociation (approximately $9 \mathrm{~h}$ vs $25 \mathrm{~h}$ ) from the $\mathrm{LH}$ receptor in comparison to hCG $[34,41]$. In addition, a separate study has shown that recombinant hCG (rhCG) activation of the receptor induces faster cAMP accumulation in comparison to recombinant human LH (rhLH) $(68.82 \pm 22.30 \mathrm{pM}$ vs $459.49 \pm 105.35$ $\mathrm{pM})$, suggesting different kinetics with the receptor between the two hormones [34]. Overall, preclinical data suggest that hCG dissociates from the receptor more slowly than $\mathrm{LH}$, which leads to an increased duration of action of approximately $16 \mathrm{~h}$ displayed at the LH/CGR and an increased potency for intracellular signalling activation [34]. Further studies are required to confirm the biological activity of the differential binding affinities of each hormone [30, 34].

\section{Molecular evaluation of LH or hCG action on follicle cells in vivo}

Over the last decade, the primary role of LH bioactivity in oocyte competence has been clarified from studies in animal models (mouse and bovine) [42-45] and human ART experience [46]. These studies indicated that the epidermal growth factor (EGF) network is essential for LH signal transduction in the follicle and have provided insights into how this signalling network coordinates nuclear and cytoplasmic maturation in the oocyte before ovulation. In mural granulosa, mobilisation and release of the three EGF-like factors, amphiregulin, epiregulin and betacellulin at ovulation are dependent on an increasingly sustained tonus of LH in the last days before ovulation $[42,43]$. The LH tonus in the days before ovulation will also determine the steroid production in the follicle (see "Function in Reproduction" section for further details), which influences the subsequent implantation capacity in a natural cycle [44-46]. Hence, LH bioactivity will affect the ripening of the follicle and determine oocyte potential for implantation.

As illustrated throughout this review, LH bioactivity during ART treatment can be heavily influenced by the stimulation regimen chosen (type of gonadotrophinreleasing hormone ( $\mathrm{GnRH})$ co-treatment, type of gonadotrophin preparation, and the type of ovulation trigger applied). Based on early studies using rLH as an ovulatory stimulus, it is clear that prolonged LH bioactivity would be needed to prevent shortening of the luteal phase and support corpus luteum function and endometrial preparation [47]. Several reports have pointed to major differences at the gene-expression and protein level in granulosa and cumulus cells obtained at in vitro fertilisation (IVF) pick-up depending on: (i) whether the stimulation regimen included $\mathrm{LH}$ bioactivity ( $\mathrm{rFSH}$ alone vs supplemental LH bioactivity) $[48,49]$ and (ii) the compounds used for ovulation triggering (hCG trigger vs $\mathrm{GnRH}$ agonist trigger) [50,51]. Although the use of a $\mathrm{GnRH}$ agonist trigger in an antagonist stimulation treatment has firmly reduced the risks of hyperstimulation, it is not always as effective as the conventional hCG trigger in terms of maturation of oocytes and supporting the luteal phase. When a GnRH agonist trigger is administered, the response is uniquely driven by $\mathrm{LH}$ and $\mathrm{FSH}$, which are mobilised depending on pituitary reserve availability. Whereas, injection of an hCG trigger delivers 'long acting' LH bioactivity, without increasing FSH level [52]. It has been suggested that a double trigger (an agonist trigger concomitant with an hCG dose) might induce a more effective stimulation trigger via the additional pituitary mobilisation of FSH. Based on the gene signatures obtained from granulosa cells, double triggering may lead to improved oocyte and embryo quality compared with hCG triggering alone $[53,54]$.

\section{Function in reproduction}

The diverse activities exhibited by hCG and LH at the LH/CGR, and the different intracellular signalling pathways activated by these hormones, are all indicators of the distinct functions that each hormone plays in reproduction $[18,55]$. Although it is widely accepted that LH primarily acts to regulate follicular growth, development and maturation, recent evidence suggests that hCG may also have an important role throughout the menstrual cycle and in menopausal women $[8,27,56,57]$. 
LH is produced at a consistent level during the early follicular phase of a normal menstrual cycle, stimulating steroidogenesis and the conversion of pregnenolone to androgens within ovarian follicular theca cells. Follicular granulosa cells undergo simultaneous stimulation by FSH, resulting in the production of the enzyme aromatase, which converts androgens produced in the theca cells to oestrogens $[2,58]$. This is known as the 'two-cell, two-gonadotrophin' theory of follicular development, and it is thought that the resultant increase in oestradiol levels within the follicular microenvironment may assist in the selection of a dominant follicle [59]. A surge in $\mathrm{LH}$ levels at the midpoint in the menstrual cycle, induced via a positive feedback mechanism due to rising oestradiol secreted by the preovulatory follicle, triggers ovulation of the mature follicle. The LH surge also stimulates the initial formation of the corpus luteum, luteinisation of the granulosa cells and early progesterone synthesis [59].

The traditional view is that, after implantation, hCG produced by the trophoblast cells is believed to take over the control of progesterone production by granulosa and corpus luteal cells from LH [29]. Progesterone is vital to promote and maintain pregnancy at this early stage as it primes the endometrium for implantation of the forthcoming embryo and prevents menstrual bleeding, continuing to support the endometrial organisation for 3-4 weeks following a successful implantation. Although hCG only promotes progesterone production for the first 3-4 weeks, the hCG concentration continues to rise, reaching its peak at 10 weeks' gestation $[8,29]$. At this point, the placenta takes over the production of hCG, with levels gradually reducing over the remaining weeks [60-62]. The presence of hCG throughout the entire duration of pregnancy, however, indicates a role beyond progesterone production [29]. Additional known functions of hCG include: promoting angiogenesis and vasculogenesis of the uterine vasculature to increase the blood supply to the placenta and developing foetus; promoting the fusion and differentiation of placental cytotrophoblasts into syncytiotrophoblasts (which, in turn, produce more hCG); promoting growth and differentiation of foetal organs; promoting umbilical cord growth; and development and inhibition of macrophage function to prevent rejection of the foetal and placental tissue $[8,18,29,61,63,64]$.

Pituitary hCG secretions can be seen to mimic the pulsatile pattern of $\mathrm{LH}$ expression throughout the normal menstrual cycle, with hCG peaking in parallel with the LH surge, albeit on average at only $3 \%$ of the concentration of LH $[2,8,65,66]$. It has been suggested that the longer circulatory half-life of hCG may increase the peak range of LH activity, with evidence from 185 women indicating that up to one-third of the LH activity during the follicular phase may be derived from $\mathrm{hCG}[2,8,9]$.
Together, these data suggest that hCG function may overlap with that of LH throughout the menstrual cycle and support LH in the stimulation of follicular maturation and induction of ovulation, as well as supporting a rise in progesterone levels during the early luteal phase $[8,18]$. There is, nevertheless, also a possibility that hCG production is incidental, occurring as a result of $\mathrm{GnRH}-$ mediated LH and FSH secretion from the pituitary [8].

A study by Snyder et al. (2005) provided data indicating that hCG levels increase with age, and concentrations of $>5 \mathrm{IU} / \mathrm{L}$ in post-menopausal women should be considered to be normal [57]. Considering that standard tests use a cut-off concentration of $>5 \mathrm{IU} / \mathrm{L}$ hCG for a positive pregnancy, this is of clinical importance as women of menopausal age are at risk of receiving falsepositive results [57]. This also provides further evidence for a role of hCG outside of pregnancy.

Owing to the similarities in their molecular structures and data indicating that hCG has a role throughout the menstrual cycle, LH and hCG are currently used interchangeably in ART protocols to drive OS $[1,67]$.

\section{Evolution of the pharmacological use of hCG and LH in ART}

The prospect of developing gonadotrophin preparations for clinical use was first explored over a century ago; researchers hoped to harness the physiological actions of the naturally occurring hormones for clinical use to induce OS in infertile women in an attempt to achieve a successful pregnancy. Since then, a number of different gonadotrophin preparations have been produced and successfully used for OS in ART (Table 1). The first hCG preparation was extracted from human placental tissue and made commercially available in 1931. Initial investigations by Ascheim and Zondek in 1927 revealed that hCG in the blood and urine of pregnant women was able to induce follicular maturation and ovulation when injected into female mice, and subsequent investigations showed hCG production to be localised to the placenta $[73,74]$. Clinical use of this preparation showed that, when administered alone, hCG was unable to promote either follicular development or ovulation, hence indicating that FSH stimulation is vital during the follicular phase [73].

Gonadotrophins extracted from the urine of postmenopausal women, known as human menopausal gonadotrophin (hMG), have traditionally been used to stimulate folliculogenesis in ART. The first purified preparations from urine contained a mixture of FSH, hCG and LH in varying amounts, sometimes with as little as $5 \%$ purity [73-75]. Improvements in purification techniques enabled the development of standardised batches of hMG containing $75 \mathrm{IU}$ each of LH and FSH activity, as well as the individual development of urinary $\mathrm{FSH}$ or urinary 
Table 1 Gonadotrophin products used in ovarian stimulation [21, 68-72]

\begin{tabular}{|c|c|c|}
\hline Brand name & Urinary/recombinant & Active ingredients \\
\hline $\begin{array}{l}\text { Menopur }^{\oplus} \\
\text { Merional }^{\oplus}\end{array}$ & Urinary & $\begin{array}{l}\text { Highly purified human menopausal gonadotrophin } \\
\text { (FSH + hCG) }\end{array}$ \\
\hline $\begin{array}{l}\text { Humegon }^{\circledast} \\
\text { Menogon }^{\circledR} \\
\text { Pergonal }^{\circledR} \\
\text { Repronex }^{\circledast}\end{array}$ & Urinary & Human menopausal gonadotrophin (FSH + LH) \\
\hline $\begin{array}{l}\text { Fostimon }^{\circledast} \\
\text { Bravelle }^{\oplus} \\
\text { Metrodin }{ }^{\circledast} \\
\text { Fertinex } \\
\text { Fertinorm }\end{array}$ & Urinary & Urofollitropin (highly purified FSH) \\
\hline 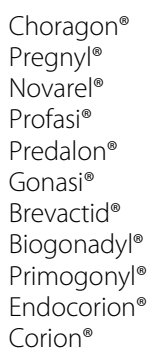 & Urinary & Human chorionic gonadotrophin (hCG) \\
\hline Gonal- $F^{\oplus}$ & Recombinant & Follitropin alfa (rFSH) \\
\hline $\begin{array}{l}\text { Puregon }^{\circledast} \\
\text { Follistim }^{\circledast}\end{array}$ & Recombinant & Follitropin beta $(\mathrm{rFSH})$ \\
\hline Elonva ${ }^{\oplus}$ & Recombinant & Corifollitropin alfa (long-acting rFSH) \\
\hline Pergoveris ${ }^{\circledast}$ & Recombinant & Follitropin alfa and lutropin alfa (rFSH and rLH) \\
\hline Luveris $^{\oplus}$ & Recombinant & Lutropin alfa (rLH) \\
\hline $\begin{array}{l}\text { Ovitrelle } \\
\text { Ovidrelle } \\
\text { Ovidrel }^{\circledast}\end{array}$ & Recombinant & Recombinant human chorionic gonadotrophin ( $\mathrm{rhCG}$ \\
\hline
\end{tabular}

FSH follicle-stimulating hormone, $h C G$ human chorionic gonadotrophin, $L H$ luteinising hormone, $r F S H$ recombinant follicle-stimulating hormone, rhCG recombinant human chorionic gonadotrophin, $r \mathrm{LH}$ recombinant luteinising hormone

LH preparations $[21,73]$. Highly purified FSH (HP-FSH) became widely available in 1995 and contained < $0.1 \mathrm{IU}$ of LH activity [76]. It was extracted to yield an increase in purity from 1 to $95 \%$ (containing only 5\% biological contamination), which has allowed for a reduction in the amount of injected protein so that it could be delivered subcutaneously at a much smaller dose than the original purified FSH [73, 74]. Commercially available, highly purified hMG (HP-hMG) was subsequently developed, containing a 1:1 ratio of FSH (75 IU) and LH bioactivity (75 IU) that was predominantly derived from hCG [77]. In parallel to the evolution of urinary-derived gonadotrophins, recombinant gonadotrophins were developed. Licensed for marketing in 1995, rFSH alfa derived from Chinese hamster ovary cells was the first available recombinant gonadotrophin preparation [73]. Further recombinant gonadotrophins have been developed and launched on the market since then, including $\mathrm{rLH}$, rhCG, the combined product of recombinant follitropin alfa ( $\mathrm{rFSH}$ alfa) and recombinant lutropin alfa in a 2:1 ratio and, more recently, long-acting $\mathrm{rFSH}$ alfa and the first human cell-line-derived $\mathrm{rFSH}$ delta [68-70, 74].
Despite a lack of evidence, it was assumed that recombinant products would demonstrate an improved batchto-batch consistency compared with urinary-derived products. However, the new generation of highly purified urinary-derived gonadotrophin products, such as Menopur, present a high standard of batch-to-batch consistency that is actually equivalent to that of recombinant products, such as Gonal-F $\mathrm{F}^{\bullet}$ [77].

Following their introduction into the market, urinaryderived and recombinant gonadotrophins have been used in an equivalent manner for OS. A number of large clinical trials have investigated different gonadotrophin preparations (Table 2), which is leading to an improved understanding of the clinical differences between hCG and LH supplementation in OS.

\section{Clinical differences between hCG and LH}

End of stimulation endocrine environment and the impact on clinical outcomes

It is essential to consider all aspects when choosing the most appropriate gonadotrophin therapy for OS as different treatments could affect the end-of-stimulation 


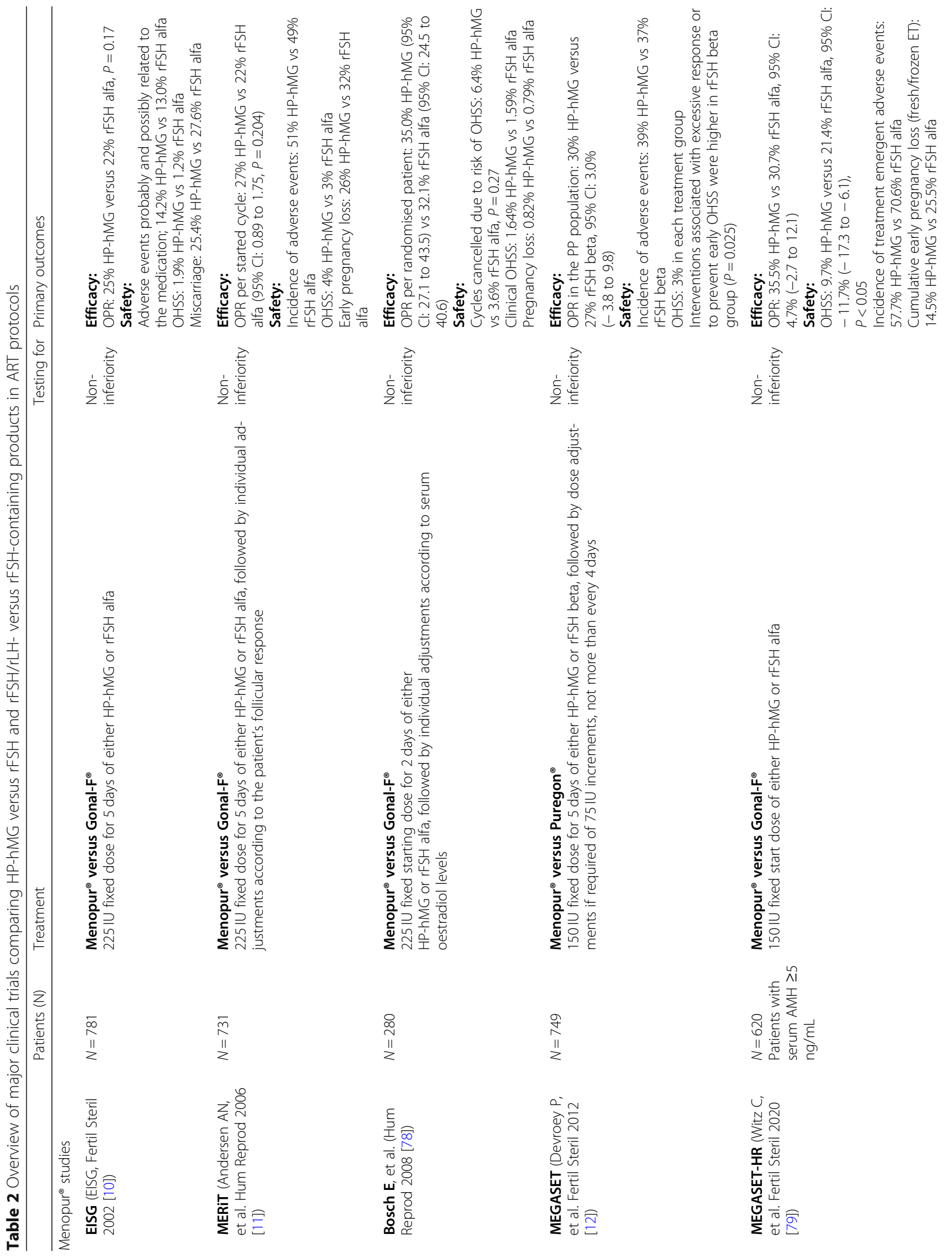




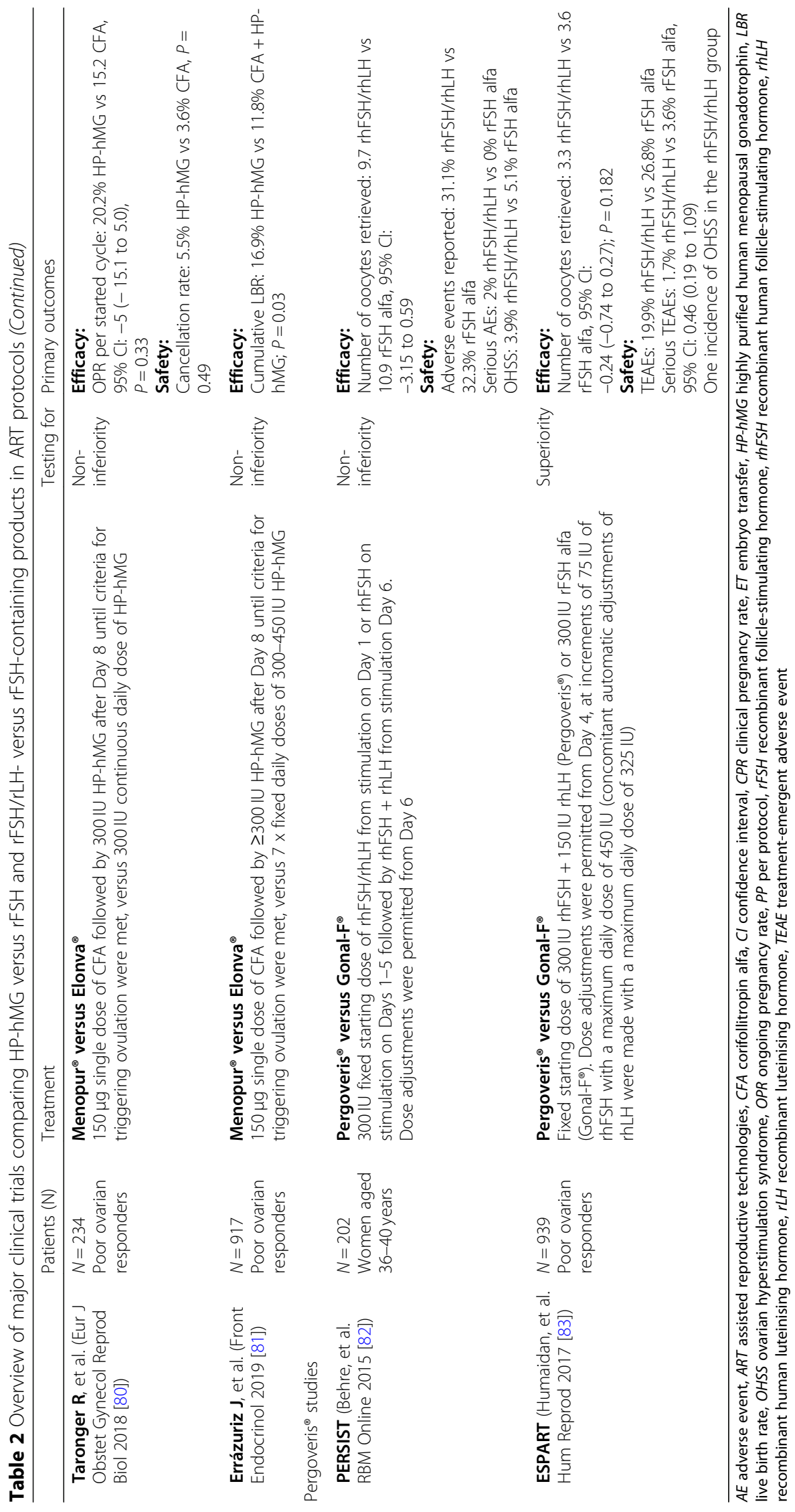


endocrine environments, consequently impacting clinical outcomes and the overall goal of achieving a live birth. The MERiT trial (a prospective, randomised, controlled, multicentre study), primarily investigated the clinical outcome of 731 IVF patients treated with HP-hMG $\left(\right.$ Menopur $\left.{ }^{\circ}\right)$ versus $\mathrm{rFSH}$ alfa $\left(\right.$ Gonal- $\left.\mathrm{F}^{\circ}\right)$, while also collecting data on the endocrine profiles achieved in the patients following treatment $[11,84]$. The trial was the subject of a post-hoc analysis carried out by Smitz et al., who found that, although there was no significant difference on stimulation Day $6(P=0.333)$, progesterone levels were significantly higher at the end of stimulation in the $\mathrm{rFSH}$ alfa group versus HP-hMG treatment (23\% higher on the last day of stimulation, $3.4 \pm 1.7 \mathrm{nmol} / \mathrm{L}$ vs $2.6 \pm 1.3 \mathrm{nmol} / \mathrm{L}, P<0.001$; and $31 \%$ higher at oocyte retrieval, $36.3 \pm 25$ vs $24.5 \pm 15.6, P<0.001$ ) [84]. The significance remained when adjusting for ovarian response (28\% higher at the end of stimulation when adjusting for the number of follicles and $29 \%$ higher at oocyte retrieval when adjusting for the number of oocytes retrieved). In addition, a higher number of patients developed progesterone levels of $>4 \mathrm{nmol} / \mathrm{L}$ at the end of stimulation in the rFSH alfa group compared with the HP-hMG group ( $23 \%$ vs $11 \%$, respectively), which was linked with reduced pregnancy rates [11, 84]. Oestradiol levels were found to be significantly higher by $20 \%$ in the $\mathrm{rFSH}$ alfa group on Day 6 of stimulation $(1.1 \pm 1.0 \mathrm{vs}$ $1.0 \pm 0.9, P=0.004), 10 \%$ higher in the HP-hMG group by end of stimulation $(7.2 \pm 4.3$ vs $6.6 \pm 4.0, P=0.031)$ and $16 \%$ higher at oocyte retrieval $(3.9 \pm 2.1$ vs $3.4 \pm 1.9$, $P=0.001$ ) [84]. Androstenedione levels were significantly increased in the HP-hMG versus rFSH alfa group at stimulation on Day 6, last stimulation day and after oocyte retrieval (Day 6: $6.0 \pm 2.5$ vs $5.5 \pm 2.4, P=0.002$; last stimulation day: $11.9 \pm 5.2$ vs $9.5 \pm 3.8, P<0.001$; oocyte retrieval: $13.6 \pm 5.5$ vs $10.8 \pm 4.2, P<0.001)$. When considering these results in combination with the outcomes of ongoing pregnancy rate (OPR) and live birth rate (LBR) from the primary study (OPR: $27 \%$ with HP-hMG group vs $22 \%$ with $\mathrm{rFSH}$ alfa, $P=0.204$; LBR: $26 \% \mathrm{HP}$ hMG vs $22 \%$ rFSH alfa, $P=0.236$ ), the data suggest that the differences in outcome observed between the HPhMG and rFSH alfa groups may have been influenced by the different endocrine profiles induced by the respective treatments [11].

This hypothesis is further supported by the results from a retrospective study that analysed progesterone levels and OPR in more than 4000 OS cycles (IVF and intracytoplasmic sperm injection [ICSI] included in the analysis) and found that OPRs are inversely correlated with progesterone levels on the day of hCG administration. In addition, this study indicated that pregnancy rates are significantly higher in women with progesterone levels $<1.5 \mathrm{ng} / \mathrm{mL}$ than in those with progesterone levels $>1.5 \mathrm{ng} / \mathrm{mL}$ [85]. Furthermore, a meta-analysis of more than 60,000 fresh, frozen-thawed and donor/recipient IVF cycles, investigating the link between progesterone levels on the day of hCG administration and pregnancy outcomes, found that elevated progesterone levels are associated with a reduced probability of pregnancy in fresh cycles only $(P<0.05$ for all thresholds defined as $\geq 0.8 \mathrm{ng} / \mathrm{mL}$ progesterone) [86]. Interestingly, elevated progesterone levels on the day of hCG administration were not associated with a reduced probability of pregnancy after frozen and donor/recipient IVF cycles, suggesting that a premature rise in progesterone levels during the follicular phase may act directly on the endometrium and impair its normal development. This may result in asynchrony between the embryo development and endometrium receptivity through advanced secretory transformations of the endometrium, thus shifting the implantation window so that it occurs earlier than normal in fresh cycles. A shifted implantation window could have subsequent detrimental effects on implantation and explain the poorer pregnancy outcomes that have been observed in clinical trials [87-93].

During assisted reproduction, ovaries are artificially stimulated in order to induce the development of multiple follicles for oocyte retrieval. In line with the 'twocell, two-gonadotrophin theory', administration of supraphysiological levels of FSH stimulates the development of multiple follicles, consequently increasing the production of progesterone [94]. Treatment supplementation with LH or hCG during the stimulation is thought to instead drive the conversion of pregnenolone to androgens (via the Delta 5 pathway), which are further converted by FSH into oestrogens, thereby limiting the conversion of pregnenolone to progesterone $[95,96]$. As a result, less progesterone is available to enter the bloodstream [88]. Data from a recent clinical trial that studied the follicular steroidogenesis pathways and progesterone levels in oocyte donors treated with either rFSH alfa or HPhMG for OS support the importance of attaining a balance of FSH and LH bioactivity when stimulating using gonadotrophins [97]. Indeed, there was a significant increase in serum progesterone following $\mathrm{rFSH}$ alfa stimulation compared with HP-hMG stimulation both on the day of trigger $(0.68 \pm 0.50 \mathrm{ng} / \mathrm{mL}$ vs $0.46 \pm 0.27 \mathrm{ng} / \mathrm{mL}$, respectively; $P=0.010$ ), and on stimulation Day 8 . Consistently, treatment with HP-hMG was associated with a significant increase in androstenedione compared with rFSH alfa $(3.0 \pm 1.4$ vs $2.4 \pm 1.1$, respectively; $P=0.015)$ on both stimulation days, and a significantly higher pregnenolone:progesterone ratio on the day of trigger $(P=0.019)$. Although the ovarian response remained comparable between the two groups $(17.5 \pm 7.9$ oocytes retrieved in the $\mathrm{rFSH}$ alfa group vs $16.5 \pm 7.5$ in the HPhMG group, $P=0.49$ ), these results indicate that 
different follicular steroidogenesis pathways are at play with $\mathrm{rFSH}$ alfa versus HP-hMG OS.

Several reviews have recently discussed the controversy surrounding the origin of premature progesterone elevation in OS based on evidence to date [90, 93, 98]. Initially, it was hypothesised that the LH bioactivity of hMG preparations may cause elevations in circulating progesterone in the context of premature LH surges. Contrary to expectations, studies comparing circulating progesterone levels following the administration of FSH or hMG revealed that FSH was associated with a similar or an increased elevation in progesterone compared with hMG (progesterone levels increased from $0.37 \pm 0.12 \mathrm{ng} /$ $\mathrm{mL}$ before FSH administration to $0.86 \pm 0.12 \mathrm{ng} / \mathrm{mL}$ approximately $15 \mathrm{~h}$ post-administration, $P<0.01[93,99])$. These data suggest that FSH stimulation alone could be associated with elevated circulatory progesterone levels at the end of stimulation, but did not distinguish between the individual influences of hCG and LH. A study by Sebag-Peyrelevade et al. (2015) analysed whether supplementation of $\mathrm{rFSH}$ alfa treatment with $\mathrm{rLH}$ could lead to comparable progesterone levels on the day of hCG triggering compared with HP-hMG (Menopur ${ }^{\circ}$ ) treatment alone. The study, conducted on pituitarydesensitised IVF patients, revealed that $\mathrm{rFSH}$ alfa supplementation with rLH was not sufficient to diminish the circulating progesterone levels to the same level as those receiving HP-hMG (median of $0.63 \mathrm{ng} / \mathrm{mL}$ for HP-hMG vs $0.91 \mathrm{ng} / \mathrm{mL}$ for $\mathrm{rLH} / \mathrm{rFSH}$ alfa median, $P<0.0001$ ). This relationship remained significant even when adjusted for the number of growing follicles to control for the extent of ovarian response $(0.055 \mathrm{ng} / \mathrm{mL} /$ growing follicle vs $0.077 \mathrm{ng} / \mathrm{mL} /$ growing follicle) [100]. A lack of effect was also reported following administration of a higher $\mathrm{rLH}$ dose in the $\mathrm{rFSH}$ alfa/rLH group: it was, therefore, suggested that the lower progesterone levels induced with HP-hMG treatment may be attributable to the hCG content (not LH) [100].

Interestingly, embryo quality may be equally as important in determining pregnancy outcomes as the endometrial receptivity induced by elevated progesterone levels. It has been suggested that patients with a good ovarian response produce oocytes/embryos of increased quality, and so may be better equipped to overcome the challenges presented by an impaired endometrial receptivity brought about by high progesterone levels. In contrast, patients with a poor ovarian response are more likely to produce oocytes of lower quality, which are less likely to be able to compensate for the impaired endometrial receptivity, thus resulting in a lower OPR [93, 98]. Data from multiple clinical trials have indicated that a progesterone level $>0.9 \mathrm{ng} / \mathrm{mL}$ on the day of hCG administration is associated with lower pregnancy rates in patients with a weak ovarian response. Therefore, it has been speculated that previous trials not reporting a link between premature elevated progesterone levels and reduced pregnancy outcomes may have unknowingly included in their analyses a majority of normal or high ovarian responders, with resulting good-quality embryos being capable of compensating for impaired endometrial receptivity [93]. Taken together, these findings indicate that OS could potentially be adapted to prevent progesterone elevation by individualisation according to a patient's predicted ovarian response and embryo quality [101].

\section{Number of oocytes retrieved and proportion of top- quality embryos achieved with different gonadotrophin preparations}

Although live birth is the most clinically meaningful goal of ART, the number of oocytes retrieved following OS is frequently used as a surrogate measure of clinical success [102]. Data from several studies indicate that $\mathrm{rFSH}$ alfa and beta trigger an increased ovarian response, in terms of number of oocytes retrieved, compared with HP-hMG. In a study by Bosch et al. (2008), in which 280 patients undergoing IVF/ ICSI were randomised to receive HP-hMG (Menopur ${ }^{\circ}$ ) or $\mathrm{rFSH}$ alfa $\left(\right.$ Gonal- $\left.\mathrm{F}^{\circ}\right)$ in $\mathrm{GnRH}$ antagonist protocols, the numbers of cumulus-oocyte complexes (COCs) retrieved and metaphase II (MII) oocytes obtained (ICSI cycles) were significantly higher with $\mathrm{rFSH}$ alfa than HP-hMG (14.4 \pm 8.1 vs $11.3 \pm 6.0, P=0.001$ and $9.7 \pm 6.0$ vs $7.8 \pm 4.0, P=0.004$, respectively) [78]. The MERiT [11] and MEGASET [12] studies also reported higher numbers of oocytes retrieved in the $\mathrm{rFSH}$ alfa and beta groups (respectively) than in the HPhMG group $(11.8 \pm 5.7$ vs $10.0 \pm 5.4, P<0.001$ and $10.7 \pm 5.8$ vs $9.1 \pm 5.2, P<0.001$, respectively). These results were further replicated in the recently concluded MEGASET-high responder (MEGASET-HR) trial, in which 620 women predicted to be high responders were randomised to receive either HP-hMG (Menopur ${ }^{\circ}$ ) or $\mathrm{rFSH}$ alfa (Gonal-F(R)) in a GnRH antagonist cycle [13, 14, 79]. As in previous studies, the number of oocytes retrieved was higher in the rFSH alfa arm than in the HP-hMG arm $(22 \pm 11.54$ vs $15.1 \pm 10.12)$ $[14,79]$. Interestingly, the PERSIST trial comparing a 2:1 formulation of $\mathrm{rFSH}$ alfa plus rLH (Pergoveris ${ }^{\circ}$ ) administered from Day 1 versus $\mathrm{rFSH}$ alfa $\left(\right.$ Gonal- $\mathrm{F}^{\circ}$ ) administered during Days 1-5 and supplemented with rLH from Day 6 of the stimulation cycle did not report a significant difference in terms of oocytes retrieved (9.7 vs $10.9,95 \%$ confidence interval $[\mathrm{CI}]:-3.15$ to 0.59 ), therefore failing to meet its primary endpoint and yielding inconclusive evidence on the influence of rLH on oocyte yield [82].

To understand whether differences in the source of LH activity affect ovarian stimulation characteristics (number of oocytes retrieved and percentage of mature oocytes) and IVF outcome, a critical appraisal of studies comparing hMG and rFSH alfa/beta + rLH was performed [103]. Of 
the 11 studies included, most were observational, with only two randomised controlled trials (RCTs) evaluated. Moreover, only one of the RCTs included compared hMG and rLH from day 1 of ovarian stimulation [104]. This RCT, performed on 111 patients, found that hMG was associated with a longer length of treatment but, surprisingly, a lower total amount of FSH administered compared with the rFSH alfa + rLH group. Notably, this study was performed in Italy at a time when only 3 oocytes were permitted to be inseminated by law, an additional reason to exert caution when interpreting these results. The author found that there was insufficient evidence to form any firm conclusions on whether the source of LH activity affects ovarian stimulation characteristics and concluded that further RCTs on this subject are needed [103].

Although studies consistently show that rFSH alfa and beta stimulation is associated with the retrieval of a higher number of oocytes than HP-hMG, the data also indicate that $\mathrm{rFSH}$ alfa/beta and HP-hMG stimulation may influence the quality of the oocytes retrieved, and this, in turn, could impact clinical outcomes. In the MERiT study, a higher proportion of retrieved oocytes developed into high-quality embryos in the HP-hMG group than in the rFSH alfa group $(11.3 \pm 16.1 \%$ versus $9.0 \pm 13.0 \%, P=0.044)[11,105]$. The MEGASET trial then reported how, despite the higher number of oocytes retrieved in the rFSH beta group, the number and quality of blastocysts on Day 5 was comparable between the two treatment arms [12]. Again, in the MEGASET-HR study, the difference in the number of oocytes retrieved, as calculated by the Hodges-Lehmann estimate, was seven fewer with HP-hMG compared with rFSH alfa, which narrowed to zero for excellent quality blastocysts (numerical difference of 0.9). MEGASET-HR also reported cumulative higher rates of early pregnancy loss in the rFSH alfa treatment arm, suggesting poor oocyte quality in comparison with the HP-hMG treatment arm [79]. Taken together, these data suggest that treatment with $\mathrm{rFSH}$ alfa/beta is likely to result in a higher oocyte yield compared with HP-hMG, but that the quality of oocytes produced with HP-hMG is proportionally higher than that produced with $\mathrm{rFSH}$ alfa/beta. Oocyte qualityrelated issues may explain why the incremental oocyte yield with $\mathrm{rFSH}$ alfa/beta does not translate into a similarly augmented abundance in numbers of good-quality blastocysts between the two groups. Furthermore, these studies also highlight why oocyte yield is not a clinically meaningful endpoint to evaluate ART efficiency.

\section{The impact of improved embryo quality on OPR and LBR} Normal responders

The higher proportion of top-quality embryos achieved with HP-hMG is suggested to be the driver for an improved implantation rate, OPR and LBR compared with $\mathrm{rFSH}$ alfa/beta in both IVF and ICSI treatment cycles $[12,105]$. Results from the MERiT study in normal responders indicated that top-quality embryos obtained from HP-hMG-treated patients are associated with a numerically higher OPR and LBR compared with topquality embryos from rFSH alfa-treated patients (OPR: $27 \%$ HP-hMG vs $22 \% \mathrm{rFSH}$ alfa, odds ratio [OR]: 1.25 , 95\% CI: 0.89 to $1.75, P=0.204$; LBR: $26 \%$ HP-hMG vs $22 \% \mathrm{rFSH}$ alfa, $P=0.236$ ) [11]. Interestingly, the concentration of hCG during the stimulation was significantly associated with LBR [106, 107]. The embryo quality in this study was assessed both by local embryologists via live microscopy (local assessment), as well as by a panel of three central embryologists via photographic evidence (central assessment). The significant difference in the proportion of top-quality embryos retrieved $(11.3 \%$ in the HP-hMG treatment arm vs $9 \%$ in the $\mathrm{rFSH}$ alfa treatment arm, $P=0.044$ ) was observed only in the local assessment [11]. Although non-significant, a similar increase in the number of top-quality embryos in the HPhMG group was identified by central assessment [105].

Subsequent investigations in normal responders in the MEGASET study provided data showing that, despite a significantly reduced number of oocytes retrieved in the HP-hMG group $(9.1 \pm 5.2$ in the HP-hMG group vs $10.7 \pm 5.8$ in the rFSH beta group, $P<0.001$ ) and a similar number of top-quality embryos between groups ( $31 \pm 30 \%$ in the HP-hMG group vs $31 \pm 28 \%$ in the rFSH beta group, $P=0.546$ ), there was a non-significant trend towards an increased OPR with HP-hMG relative to $\mathrm{rFSH}$ beta ( $30 \%$ vs $27,95 \% \mathrm{CI}$ : -3.8 to 9.8 ). Cumulative LBR, recorded for patients who underwent a single stimulation cycle with a single fresh or frozen blastocyst transfer within a year of treatment initiation, were similar in both groups, with a positive trend in favour of HPhMG (40\% HP-hMG vs 38\% rFSH beta). These results met the primary endpoint of non-inferiority and indicated that HP-hMG is as effective as rFSH beta [12].

\section{Poor responders}

The data for embryo quality, OPR and LBR have been similarly improved with HP-hMG in poor ovarian responders. Due to a reduced ovarian reserve, it can be particularly difficult to achieve a satisfactory ovarian response, measured through the number of oocytes retrieved, which can result in poor ART outcomes in this patient population. Some investigators have focused their attention on the use of long-acting products in order to increase the level of stimulation that the ovaries are subjected to, in the hope of producing a higher oocyte yield in this patient population. A recent prospective, randomised study investigated the use of a single daily dose of long-acting corifollitropin alfa (CFA) 
(Elonva ${ }^{\circ}$ ) plus HP-hMG from cycle Day 8 (HP-hMG was only administered after Day 8 if required until the criteria for ovulation triggering were achieved), compared with a continuous daily dose of HP-hMG (Menopur ${ }^{\circ}$ ) for OS in 234 patients (<40 years of age) who were at risk of poor ovarian response [80]. HP-hMG was associated with a significantly higher number of MII oocytes retrieved (3.8 vs 3.1, $P=0.04$ ), a higher number of embryos on the day of transfer (2.2 vs $1.7, P=0.05)$ and an increased number of cycles with vitrified embryos (18\% vs $9 \%, P=0.05)$. Although this did not translate into a significant difference in the number of top-quality embryos transferred (1.2 HP-hMG group vs 1.1 CFA, $P=$ 0.60 ) or the primary endpoint of OPR (20.1 vs 15.2 , $95 \%$ CI: -15.1 to -5.0$)$, there was a trend towards increased OPR, LBR and cumulative LBR in patients who received HP-hMG-only treatment, which the authors concluded may be clinically relevant. When comparing this to the retrospective analysis, which included 917 patients characterised as poor responders (according to the Bologna criteria for poor ovarian response) and treated with either a fixed daily dose of 300-450 IU of HP-hMG (Menopur ${ }^{\circ}$ ) or a single dose of CFA (Elonva ${ }^{\circ}$ ), followed by daily injections of HP-hMG from Day 8 of stimulation until the day of trigger, similar results were observed in terms of a reduced number of top-quality embryos achieved with CFA [81]. The number of COCs and MII oocytes were significantly higher for the HPhMG treatment group $(P<0.001$ and $P=0.004$, respectively), and the number of patients with at least one topquality embryo for transfer was higher in the HP-hMG group on both embryo transfer Days 3 and 5 (Day 3: 595 HP-hMG vs 444 CFA + HP-hMG, $P=0.088$; Day 5: 32 HP-hMG vs 24 CFA + HP-hMG, $P=0.724$ ). Investigators did not report significant differences in the LBR between patients treated; however, the secondary outcomes of biochemical pregnancy, clinical pregnancy and OPR were significantly higher for the HP-hMG treatment group compared with the CFA + HP-hMG group (biochemical pregnancy: $26 \%$ vs $18 \%, P=0.007$; clinical pregnancy: $23 \%$ vs $16 \%, P=0.006$; and OPR $17 \%$ vs $11 \%$, $P=0.008$ ). Additionally, HP-hMG achieved a nonsignificant, numerically higher LBR $(14 \%$ vs $10 \%, P=$ 0.09) [81]. Overall, these data indicate that HP-hMGonly protocols may be associated with increased numbers of high-quality oocytes in poor responders. This could be particularly beneficial in this patient population as expected oocyte yield in poor responders is low.

Another treatment that has been investigated in poor responders is a 2:1 formulation of $\mathrm{rFSH}$ alfa plus $\mathrm{rLH}$ $\left(\right.$ Pergoveris $\left.{ }^{\circ}\right)$. Despite its therapeutic indication solely for ovarian induction in patients with hypogonadotropic hypogonadism (severe LH and FSH deficiency), clinicians continue to use this product for OS in poor responders due to its $\mathrm{rLH}$ content. Importantly, when investigated during the ESPART trial [83], a large RCT undertaken to determine if there is a difference in the efficacy and safety of $\mathrm{rFSH}$ alfa/rLH (Pergoveris ${ }^{\circ}$ ) versus $\mathrm{rFSH}$ alfa monotherapy (Gonal- $\mathrm{F}^{\circ}$ ) when administered for OS in poor responders (classified according to a modified version of the Bologna criteria), the study failed to show superiority of $\mathrm{rFSH}$ alfa/rLH versus $\mathrm{rFSH}$ alfa monotherapy in regard to the primary endpoint of number of oocytes retrieved ( $3.3 \mathrm{rFSH}$ alfa/rLH vs $3.6 \mathrm{rFSH}$ alfa; adjusted $P$-value of 0.182 ). Furthermore, the secondary endpoints of clinical and OPR, as well as LBR, were similar between the two groups (clinical pregnancy: $14.1 \% \mathrm{rFSH}$ alfa/rLH vs $16.8 \% \mathrm{rFSH}$ alfa, $P=0.320$; OPR: $11 \% \mathrm{rFSH}$ alfa/rLH vs $12.4 \% \mathrm{rFSH}$ alfa, $P=0.599$; LBR: $10.6 \% \mathrm{rFSH}$ alfa $/ \mathrm{rLH}$ vs $11.7 \% \mathrm{rFSH}$ alfa, $P=0.663)$. The rate of biochemical pregnancy was significantly higher in the $\mathrm{rFSH}$ alfa monotherapy group $(17.3 \% \mathrm{rFSH}$ alfa/rLH vs $23.9 \% \mathrm{rFSH}$ alfa, $P=0.020$ ); however, this significance did not carry through to ongoing pregnancy. Considering these data alongside the trials comparing HP-hMG with CFA in poor responders, the results suggest that the positive outcomes in terms of oocyte yield associated with HP-hMG-only protocols may be attributable to the hCG content (not LH).

\section{High responders}

Retrospective analyses of the data from MERiT and MEGASET trials investigated the ovarian response and clinical outcomes in potential high responders [106, 108]. Women were grouped according to their serum anti-Müllerian hormone (AMH) levels, and those with $\mathrm{AMH}$ values in the highest quartile $(>5.2 \mathrm{ng} / \mathrm{ml})$ were identified as potential high responders. The analysis revealed that HP-hMG was associated with a favourable safety profile, with HP-hMG treatment resulting in a lower incidence of high response ( $\geq 15$ oocytes retrieved) compared with $\mathrm{rFSH}$ alfa/beta (MERiT: $33 \%$ in the HPhMG group vs $51 \%$ in the rFSH alfa group, $P=0.025$; MEGASET: $31 \%$ in the HP-hMG group vs $49 \%$ in the rFSH beta group, $P=0.015$ ) [106]. In the MEGASET trial, HP-hMG also showed a trend towards a lower incidence of early ovarian hyperstimulation syndrome (OHSS) and/or safety interventions due to excessive ovarian response compared with $\mathrm{rFSH}$ beta $(P=0.025)$ [108]. In addition, a shift towards an improved LBR was observed with HP-hMG compared with $\mathrm{rFSH}$ alfa/beta (combined studies: $34 \%$ in the HP-hMG group vs $22 \%$ in the $\mathrm{rFSH}$ alfa/beta group, $P=0.012$ ), despite the fact that a lower oocyte yield was achieved (MERiT: 12 in the HP-hMG group vs 15 in the rFSH alfa group, $P=0.007$; MEGASET: 12 in the HP-hMG group vs 14 in the rFSH beta group, $P=0.033)[106,108]$. These data suggest that 
HP-hMG is associated with a reduced risk of high response rates compared with $\mathrm{rFSH}$ alfa/beta, which may influence clinical outcomes in predicted high responders. Furthermore, these data indicate that a greater oocyte yield does not necessarily translate into improved pregnancy outcomes in this patient population. To investigate these findings further, a prospective trial was conducted (MEGASET-HR) specifically to analyse the effects of HP-hMG treatment in a predicted high responder population $[13,14,79]$.

The recent MEGASET-HR trial comparing HP-hMG and $\mathrm{rFSH}$ alfa in predicted high responders found that HP-hMG was associated with a trend towards increased OPR/cycle start relative to rFSH alfa (OPR $35.5 \%$ vs 30.7 , 95\% CI: -2.7 to 12.1 ), despite a reduced oocyte yield (HPhMG 15.1 vs rFSH alfa 22.2). These results may at least partly be explained by the fact that the difference in the mean number of oocytes per patient narrowed with each subsequent oocyte developmental stage analysed. Indeed, at the stage of excellent quality blastocysts, the mean difference was $0 \%$ ( $95 \% \mathrm{CI}:-1.0$ to 0.0 ) [79]. A possible theory explaining this discrepancy between treatments could be that HP-hMG, more than rFSH alfa, facilitates selection of high-quality embryos in the ovary, prior to oocyte retrieval. Cumulative live birth rate per cycle start was comparable between HP-hMG and rFSH alfa (HP-hMG 50.6\% vs rFSH alfa 51.5\%), despite a higher total number of embryos transferred in the rFSH group (HP-hMG 308 vs rFSH alfa 373). The lack of clinical efficacy conferred by a higher number of blastocysts in the rFSH alfa group could partly be explained by a higher live birth rate per transfer and lower early pregnancy loss in HP-hMG-treated subjects in both fresh and frozen transfer cycles. The MEGA SET-HR trial also reported that HP-hMG was associated with a significantly reduced rate of OHSS compared with rFSH alfa treatment (9.7\% HP-hMG vs $21.4 \% \mathrm{rFSH}$ alfa, 95\% CI: -17.3 to -6.1$)$. These findings support the noninferiority of HP-hMG versus $\mathrm{rFSH}$ alfa with respect to efficacy in patients predicted to be high responders undergoing ICSI, and suggest that the increased ovarian response and number of retrieved oocytes seen with rFSH alfa treatment in this patient group may translate into diminished pregnancy outcomes in terms of OPR, cumulative pregnancy loss and risk of OHSS $[13,14,79]$.

\section{Meta-analyses}

In addition to the aforementioned clinical trials, a number of meta-analyses have been conducted to examine the published data for pregnancy outcomes with different gonadotrophin products. Two separate metaanalyses have reported similar trends for an increased LBR and clinical pregnancy rate (CPR) with hMG: Coomarasamy et al. (2007) analysed seven studies, with a total of 2159 women, comparing hMG with rFSH alfa/ beta treatment as part of IVF/ICSI treatment within a GnRH agonist protocol [109], whereas Al-Inany and colleagues (2008) pooled data from 12 studies comparing the efficacy and safety of hMG and $\mathrm{rFSH}$ alfa/beta in 3575 women [110]. Both concluded that LBR (relative risk $[\mathrm{RR}]=1.18,95 \% \mathrm{CI}: 1.02$ to 1.38 ; OR: $1.20,95 \% \mathrm{CI}$ : 1.01 to 1.42$)$ and $\mathrm{CPR}(\mathrm{RR}=1.17,95 \% \mathrm{CI}: 1.03$ to 1.34 ; OR: $1.22,95 \%$ CI: 1.03 to 1.43 ) were significantly increased with hMG treatment versus $\mathrm{rFSH}$ alfa/beta alone.

A separate, large meta-analysis investigated pregnancy outcomes with $\mathrm{rFSH}$ alfa/beta treatment versus urinaryderived gonadotrophins (hMG, purified FSH or HPFSH), including 42 trials and more than 9000 couples in the analysis. The investigators concluded that there were no significant differences in the LBR or OHSS rates with $\mathrm{rFSH}$ alfa/beta versus all other gonadotrophin treatments combined [111], although when individual urinary gonadotrophins were considered separately there were significantly fewer live births in the $\mathrm{rFSH}$ alfa/beta group when compared with hMG alone (OR: 0.84, 95\% CI: 0.72 to $0.99 ; N=3197$ ), which is consistent with the findings of the previous two meta-analyses.

A recently published systematic review and metaanalysis investigated whether recombinant gonadotrophins differ from HP-hMG in terms of the total amount required to achieve a live birth. A total of seven RCTs with 3220 women were included, all of which directly compared $\mathrm{rFSH}$ alfa/beta with HP-hMG for OS. Although pooled analyses of the seven studies did not provide evidence of a difference in the amount of gonadotrophins used per woman that started an IVF/ ICSI cycle ( -37 IU, 95\% CI: -115 to $41 ; \mathrm{I}^{2}=68 \%$ ), it did reveal some significant differences between gonadotrophins in terms of outcomes. The difference in the mean gonadotrophin amount per extra live birth was $789 \mathrm{IU}$ (95\% CI: -9.5 to 1570 ) for $\mathrm{rFSH}$ alfa/beta versus HPhMG, and treatment with HP-hMG was associated with a significantly higher LBR compared with rFSH (RR: $0.88,95 \%$ CI: 0.78 to $0.99, P=0.03)$. There was insufficient evidence to detect a difference in cumulative LBR between $\mathrm{rFSH}$ alfa/beta and HP-hMG (RR: 0.91, 95\% CI: 0.80 to $1.04, P=0.17$ ), which may be because only three of the seven studies reported this endpoint and there were differences in cryopreservation techniques between studies.

Taken together, the clinical studies and meta-analyses discussed support of the non-inferiority of HP-hMG compared with $\mathrm{rFSH}$ alfa/beta regarding efficacy and safety. Furthermore, the growing body of evidence suggests that HP-hMG leads to incremental benefits in key pregnancy outcomes compared with $\mathrm{rFSH}$ alfa/beta, which translates to a higher LBR, as seen in metaanalyses. These benefits may be at least partly due to the 
improved oocyte quality associated with HP-hMG treatment and a better synchronisation of the endometrium, a finding reported across several clinical trials.

\section{Conclusions}

Although hCG and LH were previously believed to have overlapping roles in the reproductive system, the biological and clinical data discussed in this review highlight emerging evidence suggesting that they have distinct functional differences throughout the menstrual cycle and normal physiology, which can ultimately impact responses and outcomes in ART. However, because LH and hCG bind to a common receptor, there is an ongoing scientific debate over the optimal use of products that derive their LH bioactivity from either hCG or from LH.

Some clinicians believe that there is an established need for LH bioactivity in OS, which could be met through supplementation with rLH products. However, evidence to the contrary was provided by the PERSIST and ESPART trials, which indicated that $\mathrm{rFSH}$ alfa/rLH treatment is neither equivalent nor superior to $\mathrm{rFSH}$ alfa monotherapy for the number of oocytes retrieved, OPR or LBR, with the latter two outcomes displaying a negative trend instead. Data further suggest that poor responders may benefit from HP-hMG treatment, particularly to achieve an adequate oocyte yield. Oocyte yield is an important issue as it is thought to contribute to treatment efficacy.

Several studies, including EISG [10], MERiT [11], MEGASET [12] and MEGASET-HR [79], have consistently provided evidence in favour of LH bioactivity derived from hCG in OS $[78,80,81]$. These studies suggest that, although associated with a lower oocyte yield, HP-hMG treatment may result in a higher proportion of good-quality embryos and/or may increase endometrial receptivity compared with rFSH alfa/beta. Randomised controlled trials have indicated a consistent trend towards an improved OPR and LBR following fresh embryo transfer and HPhMG treatment. These effects may be partly related to the fact that HP-hMG is associated with a lower risk of premature progesterone rises during OS [100]. An alternative explanation could be related to the higher proportion of good-quality embryos associated with HP-hMG: could the evidence be suggesting that HP-hMG facilitates the selection of good-quality oocytes within the body, while the selection takes place in the laboratory when patients are treated with $\mathrm{rFSH}$ alfa/beta?

Overall, the studies reviewed here indicate that hCG supplementation and the use of hCG-containing products are efficacious and ultimately lead to an improved LBR in normal and poor responders. In addition, there is evidence that hCG-containing products result in at least comparable, if not reduced, rates of OHSS and/or safety interventions due to excessive ovarian response to gonadotrophin preparations in high responders. Together, these data provide robust evidence that hCGcontaining products are a valuable tool for OS in the field of ART.

\section{Abbreviations}

AC: Adenylyl cyclase enzyme; AE: Adverse event; AKT: Protein kinase B; ART: Assisted reproductive technologies; ATP: Adenosine tri-phosphate: CAMP: cyclic adenosine monophosphate; CFA: Corifollitropin alfa; CG: Chorionic gonadotrophin; Cl: Confidence interval; COC: Cumulus-oocyte complex; COOH: Carboxylic acid; CREB: CAMP response element-binding protein; CTP: Carboxy-terminal peptide; EGF: Epidermal growth factor; ERK1/ 2: Extracellular signal-regulated kinase 1/2; FSH: Follicle-stimulating hormone; GnRH: Gonadotrophin-releasing hormone; hCG: Human chorionic gonadotrophin; hLH: Human luteinising hormone; hMG: Human menopausal gonadotrophin; HP-FSH: Highly purified FSH; HP-hMG: Highly purified human menopausal gonadotrophin; ICSI: Intracytoplasmic sperm injection; IVF: In vitro fertilisation; LBR: Live birth rate; LH: Luteinising hormone; LH/ CGR: Luteinising hormone/choriogonadotrophin receptor; OHSS: Ovarian hyperstimulation syndrome; OPR: Ongoing pregnancy rate; OR: Odds ratio; OS: Ovarian stimulation; PDE: Phosphodiesterase enzyme; PKA: Protein kinase A; PI3K: Phosphoinositide 3-kinases; PP: Per protocol; RCT : Randomised controlled trial; rFSH: Recombinant follicle-stimulating hormone:"

rhCG: Recombinant hCG; rhFSH: Recombinant human follicle-stimulating hormone; rhLH: Recombinant human luteinising hormone; rLH: Recombinant

LH; TEAE: Treatment-emergent adverse event

\section{Acknowledgements \\ Writing support was provided by Christie Whitehouse, Litmus (a Syneos Health company), London, UK, and the manuscript was funded by Ferring Pharmaceuticals.}

\section{Authors' contributions}

P.P. and J.S. devised the main conceptual ideas of the manuscript. P.P. and J.S. contributed to the analysis and interpretation of the available literature and data and worked on the manuscript. P.P. and J.S. read and approved the final manuscript.

\section{Funding}

The study was supported by Ferring Pharmaceuticals.

\section{Availability of data and materials}

Not applicable.

Ethics approval and consent to participate

Not applicable.

\section{Consent for publication}

Not applicable.

\section{Competing interests}

P.P. has received speaker's fees or grants from MSD, Ferring Pharmaceuticals, Besins and Biomerieux; J.S. has conducted clinical research sponsored by Ferring Pharmaceuticals, Besins, Biomerieux and Merck.

\section{Author details}

${ }^{1}$ Follicle Biology Laboratory, Vrije Universiteit Brussel, Laarbeeklaan, 103, 1090 Brussels, Belgium. ${ }^{2}$ Centre for Reproductive Medicine, Universitair Ziekenhuis Brussel, Vrije Universiteit Brussel, Brussels, Belgium.

Received: 27 May 2020 Accepted: 29 July 2020

Published online: 06 August 2020

\section{References}

1. Choi J, Smitz J. Luteinizing hormone and human chorionic gonadotropin: origins of difference. Mol Cell Endocrinol. 2014;383:203-13. 
2. Choi J, Smitz J. Luteinizing hormone and human chorionic gonadotropin: distinguishing unique physiologic roles. Gynecol Endocrinol. 2014;30:174-81.

3. Raju GA, Chavan R, Deenadayal M, Gunasheela D, Gutgutia R, Haripriya G, et al. Luteinizing hormone and follicle stimulating hormone synergy: a review of role in controlled ovarian hyper-stimulation. J Hum Reprod Sci. 2013:6:227-34.

4. Shoham Z. The clinical therapeutic window for luteinizing hormone in controlled ovarian stimulation. Fertil Steril. 2002:77:1170-7.

5. Falck B. Site of production of oestrogen in rat ovary as studied in microtransplants. Acta Physiol Scand Suppl. 1959;47:1-101.

6. Strauss JF, Barbieri RL. Yen \& Jaffe's reproductive endocrinology: physiology, pathophysiology, and clinical management. 6th ed. Philadelphia: Elsevier; 2009.

7. Fritz MA, Speroff L. Clinical gynecologic endocrinology and infertility. 8th ed. Philadelphia: Lippincott Williams \& Wilkins; 2011.

8. Cole LA. New discoveries on the biology and detection of human chorionic gonadotropin. Reprod Biol Endocrinol. 2009;7:8.

9. Cole LA, Gutierrez JM. Production of human chorionic gonadotropin during the normal menstrual cycle. J Reprod Med. 2009:54:245-50.

10. EISG. Efficacy and safety of highly purified menotropin versus recombinant follicle-stimulating hormone in in vitro fertilization/intracytoplasmic sperm injection cycles: a randomized, comparative trial. Fertil Steril. 2002;78:520-8

11. Andersen AN, Devroey P, Arce JC. Clinical outcome following stimulation with highly purified hMG or recombinant FSH in patients undergoing IVF: a randomized assessor-blind controlled trial. Hum Reprod. 2006;21:3217-27.

12. Devroey P, Pellicer A, Nyboe Andersen A, Arce JC, Menopur in Gn RHACWSETTG. A randomized assessor-blind trial comparing highly purified hMG and recombinant FSH in a GnRH antagonist cycle with compulsory single-blastocyst transfer Fertil Steril 2012;97:561-571.

13. Witz CA, Doody K, Park J, Seifu Y, O'Brien K, Yankov V, et al. Highly purified human menotropin (HP-HMG) versus recombinant follicle stimulating hormone (RFSH) in high responders undergoing in vitro fertilization (IVF): MEGASET-HR trial outcomes. Fertil Steril. 2017;108:e21-2.

14. Doody K, Daftary GS, Seifu Y, O'Brien K, Yankov V, Heiser PW. Can treatment of patients predicted to be high-responders be improved? Insights from the menopur in $\mathrm{GnRH}$ antagonist single embryo transfer - high responder (MEGASET-HR) trial. Fertil Steril. 2018;110:e31.

15. Narayan P, Ulloa-Aguirre A, Dias JA. Chapter 2 - Gonadotropin Hormones and Their Receptors. In: Strauss JF, Barbieri RL, editors. Yen \& Jaffe's Reproductive Endocrinology: Physiology, Pathophysiology, and Clinical Management. 8th ed. Philadelphia: Elsevier; 2019. p. 25-57.e15.

16. Bahl OP. Human chorionic gonadotropin, its receptor and mechanism of action. Fed Proc. 1977:36:2119-27.

17. Norman RJ, Buck RH, De Medeiros SF. Measurement of human chorionic gonadotrophin ( $\mathrm{hCG}$ ): indications and techniques for the clinical laboratory. Ann Clin Biochem. 1990;27(Pt 3):183-94.

18. Smitz J. LH and hCG: their distinct physiological roles and use in ovarian stimulation protocols. In: Allahbadia G, Morimoto Y, editors. Ovarian stimulation protocols. New Delhi: Springer; 2016. p. 57-69.

19. Casarini L, Brigante G, Simoni M, Santi D. Clinical applications of gonadotropins in the female: assisted reproduction and beyond. Prog Mol Biol Transl Sci. 2016;143:85-119.

20. Mann K, Lamerz R, Hellmann T, Kumper HJ, Staehler G, Karl HJ. Use of human chorionic gonadotropin and alpha-fetoprotein radioimmunoassays: specificity and apparent half-life determination after delivery and in patients with germ cell tumors. Oncodev Biol Med. 1980;1:301-12.

21. Leao Rde B, Esteves SC. Gonadotropin therapy in assisted reproduction: an evolutionary perspective from biologics to biotech. Clinics. 2014;69:279-93.

22. Stenman UH, Tiitinen A, Alfthan $H$, Valmu L. The classification, functions and clinical use of different isoforms of HCG. Hum Reprod Update. 2006;12:76984.

23. Cook AS, Webster BW, Terranova PF, Keel BA. Variation in the biologic and biochemical characteristics of human menopausal gonadotropin. Fertil Steril. 1988:49:704-12.

24. Stanton PG, Pozvek G, Burgon PG, Robertson DM, Hearn MT. Isolation and characterization of human LH isoforms. J Endocrinol. 1993;138:529-43.

25. Cole LA. hCG structure: A logical perspective. Asian Pac J Reprod. 2012;1: 287-92.

26. Cole LA, Butler S. Hyperglycosylated hCG, hCGbeta and Hyperglycosylated hCGbeta: interchangeable cancer promoters. Mol Cell Endocrinol. 2012;349: 232-8.
27. Birken S, Maydelman Y, Gawinowicz MA, Pound A, Liu Y, Hartree AS Isolation and characterization of human pituitary chorionic gonadotropin. Endocrinology. 1996;137:1402-11.

28. McGregor WG, Raymoure WJ, Kuhn RW, Jaffe RB. Fetal tissue can synthesize a placental hormone. Evidence for chorionic gonadotropin beta-subunit synthesis by human fetal kidney. J Clin Invest. 1981;68:306-9.

29. Cole LA. Biological functions of hCG and hCG-related molecules. Reprod Biol Endocrinol. 2010:8:102

30. Casarini L, Riccetti L, De Pascali F, Nicoli A, Tagliavini S, Trenti T, et al. Follicle-stimulating hormone potentiates the steroidogenic activity of chorionic gonadotropin and the anti-apoptotic activity of luteinizing hormone in human granulosa-lutein cells in vitro. Mol Cell Endocrinol. 2016; 422:103-14.

31. Fares FA, Suganuma N, Nishimori K, LaPolt PS, Hsueh AJ, Boime I. Design of a long-acting follitropin agonist by fusing the $\mathrm{C}$-terminal sequence of the chorionic gonadotropin beta subunit to the follitropin beta subunit. Proc Natl Acad Sci U S A. 1992:89:4304-8.

32. Duijkers IJ, Klipping C, Boerrigter PJ, Machielsen CS, De Bie JJ, Voortman G. Single dose pharmacokinetics and effects on follicular growth and serum hormones of a long-acting recombinant FSH preparation (FSH-CTP) in healthy pituitary-suppressed females. Hum Reprod. 2002:17:1987-93.

33. le Contonnec JY, Porchet HC, Beltrami V, Khan A, Toon S, Rowland M. Clinical pharmacology of recombinant human follicle-stimulating hormone. II. Single doses and steady state pharmacokinetics. Fertil Steril. 1994;61:67986.

34. Riccetti L, Yvinec R, Klett D, Gallay N, Combarnous Y, Reiter E, et al. Human luteinizing hormone and chorionic gonadotropin display biased Agonism at the LH and LH/CG receptors. Sci Rep. 2017;7:940.

35. Dufau ML. THE LUTEINIZING HORMONE RECEPTOR. Annu Rev Physiol. 1998; 60:461-96.

36. Galet C, Ascoli M. The differential binding affinities of the luteinizing hormone (LH)/choriogonadotropin receptor for $\mathrm{LH}$ and choriogonadotropin are dictated by different extracellular domain residues. Mol Endocrinol. 2005;19:1263-76.

37. Casarini L, Lispi M, Longobardi S, Milosa F, La Marca A, Tagliasacchi D, et al. $\mathrm{LH}$ and $\mathrm{hCG}$ action on the same receptor results in quantitatively and qualitatively different intracellular signalling. PLoS One. 2012;7:e46682.

38. Gupta C, Chapekar T, Chhabra Y, Singh P, Sinha S, Luthra K. Differential response to sustained stimulation by $\mathrm{hCG} \& \mathrm{LH}$ on goat ovarian granulosa cells. Indian J Med Res. 2012;135:331-40.

39. Riccetti L, De Pascali F, Gilioli L, Potì F, Giva LB, Marino M, et al. Human LH and hCG stimulate differently the early signalling pathways but result in equal testosterone synthesis in mouse Leydig cells in vitro. Reprod Biol Endocrinol. 2017;15:2.

40. Huhtaniemi IT, Catt KJ. Differential binding affinities of rat testis luteinizing hormone $(\mathrm{LH})$ receptors for human chorionic gonadotropin, human $\mathrm{LH}$, and ovine LH. Endocrinology. 1981;108:1931-8.

41. Klett $D$, Meslin P, Relav L, Nguyen TM, Mariot J, Jegot G, et al. Low reversibility of intracellular cAMP accumulation in mouse Leydig tumor cells (MLTC-1) stimulated by human luteinizing hormone $(\mathrm{hLH})$ and chorionic gonadotropin (hCG). Mol Cell Endocrinol. 2016:434:144-53.

42. Park JY, Su YQ, Ariga M, Law E, Jin SL, Conti M. EGF-like growth factors as mediators of LH action in the ovulatory follicle. Science. 2004:303:682-4.

43. Hsieh M, Lee D, Panigone S, Horner K, Chen R, Theologis A, et al. Luteinizing hormone-dependent activation of the epidermal growth factor network is essential for ovulation. Mol Cell Biol. 2007;27:1914-24.

44. Sirard MA. Somatic environment and germinal differentiation in antral follicle: the effect of FSH withdrawal and basal LH on oocyte competence acquisition in cattle. Theriogenology. 2016;86:54-61.

45. Nivet AL, Vigneault C, Blondin P, Sirard MA. Influence of luteinizing hormone support on granulosa cells transcriptome in cattle. Anim Sci J. 2018:89:21-30

46. Zamah AM, Hsieh M, Chen J, Vigne JL, Rosen MP, Cedars MI, et al. Human oocyte maturation is dependent on $\mathrm{LH}$-stimulated accumulation of the epidermal growth factor-like growth factor, amphiregulin. Hum Reprod. 2010:25:2569-78.

47. Beckers NG, Macklon NS, Eijkemans MJ, Ludwig M, Felberbaum RE, Diedrich $K$, et al. Nonsupplemented luteal phase characteristics after the administration of recombinant human chorionic gonadotropin recombinant luteinizing hormone, or gonadotropin-releasing hormone $(\mathrm{GnRH})$ agonist to induce final oocyte maturation in in vitro fertilization 
patients after ovarian stimulation with recombinant follicle-stimulating hormone and GnRH antagonist cotreatment. J Clin Endocrinol Metab. 2003; 88:4186-92.

48. Grondahl ML, Borup R, Lee YB, Myrhoj V, Meinertz H, Sorensen S. Differences in gene expression of granulosa cells from women undergoing controlled ovarian hyperstimulation with either recombinant follicle-stimulating hormone or highly purified human menopausal gonadotropin. Fertil Steril. 2009;91:1820-30

49. Adriaenssens T, Wathlet S, Segers I, Verheyen G, De Vos A, Van der Elst J, et al. Cumulus cell gene expression is associated with oocyte developmental quality and influenced by patient and treatment characteristics. Hum Reprod. 2010;25:1259-70.

50. Humaidan P, Westergaard LG, Mikkelsen AL, Fukuda M, Yding AC. Levels of the epidermal growth factor-like peptide amphiregulin in follicular fluid reflect the mode of triggering ovulation: a comparison between gonadotrophin-releasing hormone agonist and urinary human chorionic gonadotrophin. Fertil Steril. 2011;95:2034-8.

51. Cerrillo M, Pacheco A, Rodriguez S, Gomez R, Delgado F, Pellicer A, et al. Effect of GnRH agonist and hCG treatment on VEGF, angiopoietin-2, and VEcadherin: trying to explain the link to ovarian hyperstimulation syndrome. Fertil Steril. 2011:95:2517-9.

52. Gonen Y, Balakier H, Powell W, Casper RF. Use of gonadotropin-releasing hormone agonist to trigger follicular maturation for in vitro fertilization. J Clin Endocrinol Metab. 1990;71:918-22.

53. Haas J, Ophir L, Barzilay E, Machtinger R, Yung Y, Orvieto R, et al. Standard human chorionic gonadotropin versus double trigger for final oocyte maturation results in different granulosa cells gene expressions: a pilot study. Fertil Steril. 2016:106:653-9 e1.

54. Caixeta ES, Machado MF, Ripamonte P, Price C, Buratini J. Effects of FSH on the expression of receptors for oocyte-secreted factors and members of the EGF-like family during in vitro maturation in cattle. Reprod Fertil Dev. 2013;25:890-9.

55. Speroff L, Fritz M. Clinical gynecologic endocrinology and infertility. 7th ed. Philadelphia: Lippincott Williams \& Wilkins; 2005.

56. Cole LA, Khanlian SA, Muller CY. Detection of perimenopause or postmenopause human chorionic gonadotropin: an unnecessary source of alarm. Am J Obstet Gynecol. 2008;198:275.e1-7.

57. Snyder JA, Haymond S, Parvin CA, Gronowski AM, Grenache DG. Diagnostic considerations in the measurement of human chorionic gonadotropin in aging women. Clin Chem. 2005;51:1830-5.

58. Drummond AE. The role of steroids in follicular growth. Reprod Biol Endocrinol. 2006:4:16.

59. Reed BG, Carr BR. The Normal menstrual cycle and the control of ovulation. In: Feingold KR, Anawalt B, Boyce A, et al, editors. Endotext. MDText.com, Inc. 2000. https://www.ncbi.nlm.nih.gov/pubmed/25905282. Accessed 10 Oc 2019.

60. Dante $G$, Vaccaro $V$, Facchinetti $F$. Use of progestagens during early pregnancy. Facts Views Vis Obgyn. 2013;5:66-71.

61. Shi QJ, Lei ZM, Rao CV, Lin J. Novel role of human chorionic gonadotropin in differentiation of human cytotrophoblasts. Endocrinology. 1993;132:1387-95.

62. Tal R, Taylor HS, Burney RO, Mooney SB, Giudice LC. Endocrinology of pregnancy. In: Feingold KR, Anawalt B, Boyce A, et al, editors. Endotext. MDText.com, Inc. 2000. https://www.ncbi.nlm.nih.gov/pubmed/25905197. Accessed 10 Oct 2019

63. Zygmunt M, Herr F, Keller-Schoenwetter S, Kunzi-Rapp K, Munstedt K, Rao $\mathrm{CV}$, et al. Characterization of human chorionic gonadotropin as a novel angiogenic factor. J Clin Endocrinol Metab. 2002;87:5290-6.

64. Berndt S, Blacher S, Perrier d'Hauterive S, Thiry M, Tsampalas M, Cruz A, et al. Chorionic gonadotropin stimulation of angiogenesis and pericyte recruitment. J Clin Endocrinol Metab. 2009;94:4567-74

65. Odell WD, Griffin J. Pulsatile secretion of human chorionic gonadotropin in normal adults. N Engl J Med. 1987:317:1688-91.

66. Hartree AS, Shownkeen RC, Stevens VC, Matsuura S, Ohashi M, Chen HC. Studies of the human chorionic gonadotrophin-like substance of human pituitary glands and its significance. J Endocrinol. 1983;96:115-26.

67. Casarini L, Santi D, Brigante G, Simoni M. Two hormones for one receptor: evolution, biochemistry, actions, and pathophysiology of LH and hCG. Endocr Rev. 2018:39:549-92.

68. Merck Serono. Pergoveris Summary of Product Characteristics. https://www. ema.europa.eu/en/documents/product-information/pergoveris-eparproduct-information_en.pdf. Accessed 9 July 2019.

69. N.V. Organon. Elonva Summary of Product Characteristics. https://www.ema. europa.eu/en/medicines/human/EPAR/elonva. Accessed 9 July 2019.
70. Ferring Pharmaceuticals. Rekovelle Summary of Product Characteristics. https://www.ema.europa.eu/en/documents/product-information/rekovelleepar-product-information_en.pdf. Accessed 9 July 2019.

71. Santi D, Casarini L, Alviggi C, Simoni M. Efficacy of Follicle-Stimulating Hormone (FSH) Alone, FSH + Luteinizing Hormone, Human Menopausal Gonadotropin or FSH + Human Chorionic Gonadotropin on Assisted Reproductive Technology Outcomes in the "Personalized" Medicine Era: A Meta-analysis. Front Endocrinol (Lausanne). 2017:8:114.

72. IBSA Farmaceutici. Fostimon Summary of Product Characteristics https://www. pharmasure.co.uk/uploads/fostimon-75iu-smpc.pdf. Accessed 9 July 2019.

73. Lunenfeld B. Historical perspectives in gonadotrophin therapy. Hum Reprod Update. 2004;10:453-67.

74. Practice Committee of the American Society for Reproductive Medicine. Definitions of infertility and recurrent pregnancy loss. Fertil Steril. 2008;90(5 Suppl):S60.

75. Gurin S, Bachman G, Wilson D. The gonadotropic hormone of urine of pregnancy. ii) chemical studies of preparations having high biological activity. J Biol Chem 1940;133:467-476.

76. Zwart-van Rijkom JE, Broekmans FJ, Leufkens HG. From HMG through purified urinary FSH preparations to recombinant FSH: a substitution study. Hum Reprod. 2002;17:857-65.

77. Wolfenson C, Groisman J, Couto AS, Hedenfalk M, Cortvrindt RG, Smitz JE, et al. Batch-to-batch consistency of human-derived gonadotrophin preparations compared with recombinant preparations. Reprod BioMed Online. 2005;10:442-54.

78. Bosch E, Vidal C, Labarta E, Simon C, Remohi J, Pellicer A. Highly purified hMG versus recombinant FSH in ovarian hyperstimulation with $\mathrm{GnRH}$ antagonists--a randomized study. Hum Reprod. 2008:23:2346-51.

79. Witz CA, Daftary GS, Doody KJ, Park JK, Seifu Y, Yankov V, et al. Randomized, assessor-blinded trial comparing highly purified human menotropin and recombinant follicle-stimulating hormone in high responders undergoing intracytoplasmic sperm injection. Fertil Steril. 2020;114:321-30.

80. Taronger R, Martinez-Cuenca S, Ferreros I, Rubio JM, Fernandez-Colom PJ, Martinez-Triguero $\mathrm{ML}$, et al. Ovarian stimulation with corifollitropin alfa followed by hp-hMG compared to hp-hMG in patients at risk of poor ovarian response undergoing ICSI: a randomized controlled trial. Eur J Obstet Gynecol Reprod Biol. 2018;231:192-7.

81. Errazuriz J, Romito A, Drakopoulos P, Frederix B, Racca A, De Munck N, et al. Cumulative Live Birth Rates Following Stimulation With Corifollitropin Alfa Compared With hp-hMG in a GnRH Antagonist Protocol in Poor Ovarian Responders. Front Endocrinol (Lausanne). 2019;10:175.

82. Behre HM, Howles CM, Longobardi S. Randomized trial comparing luteinizing hormone supplementation timing strategies in older women undergoing ovarian stimulation. Reprod BioMed Online. 2015;31:339-46.

83. Humaidan P, Chin W, Rogoff D, D'Hooghe T, Longobardi S, Hubbard J, et al. Efficacy and safety of follitropin alfa/lutropin alfa in ART: a randomized controlled trial in poor ovarian responders. Hum Reprod. 2017;32:544-55.

84. Smitz J, Andersen AN, Devroey P, Arce JC. Endocrine profile in serum and follicular fluid differs after ovarian stimulation with HP-hMG or recombinant FSH in IVF patients. Hum Reprod. 2007;22:676-87.

85. Bosch E, Labarta E, Crespo J, Simon C, Remohi J, Jenkins J, et al. Circulating progesterone levels and ongoing pregnancy rates in controlled ovarian stimulation cycles for in vitro fertilization: analysis of over 4000 cycles. Hum Reprod. 2010;25:2092-100.

86. Venetis CA, Kolibianakis EM, Bosdou JK, Tarlatzis BC. Progesterone elevation and probability of pregnancy after IVF: a systematic review and metaanalysis of over 60000 cycles. Hum Reprod Update. 2013;19:433-57.

87. Fanchin R, Righini C, Olivennes F, Taieb J, de Ziegler D, Frydman R. Computerized assessment of endometrial echogenicity: clues to the endometrial effects of premature progesterone elevation. Fertil Steril. 1999;71:174-81.

88. Fleming $\mathrm{R}$, Jenkins $\mathrm{J}$. The source and implications of progesterone rise during the follicular phase of assisted reproduction cycles. Reprod BioMed Online. 2010;21:446-9.

89. Kasum M, Simunic V, Vrcic H, Stanic P, Oreskovic S, Beketic-Oreskovic L. Follicular progesterone elevations with ovulation induction for IVF. Gynecol Endocrinol. 2014:30:537-41.

90. Lawrenz B, Fatemi HM. Effect of progesterone elevation in follicular phase of IVFcycles on the endometrial receptivity. Reprod BioMed Online. 2017:34:422-8.

91. Chetkowski RJ, Kiltz RJ, Salyer WR. In premature luteinization, progesterone induces secretory transformation of the endometrium without impairment of embryo viability. Fertil Steril. 1997;68:292-7. 
92. Melo MA, Meseguer M, Garrido N, Bosch E, Pellicer A, Remohi J. The significance of premature luteinization in an oocyte-donation programme. Hum Reprod. 2006;21:1503-7.

93. Adda-Herzog E, Poulain M, de Ziegler D, Ayoubi JM, Fanchin R. Premature progesterone elevation in controlled ovarian stimulation: to make a long story short. Fertil Steril. 2018;109:563-70.

94. Andersen CY, Ezcurra D. Human steroidogenesis: implications for controlled ovarian stimulation with exogenous gonadotropins. Reprod Biol Endocrinol. 2014;12:128.

95. Fortune JE, Armstrong DT. Androgen production by theca and granulosa isolated from proestrous rat follicles. Endocrinology. 1977;100:1341-7.

96. Moon YS, Tsang BK, Simpson C, Armstrong DT. 17 beta-estradiol biosynthesis in cultured granulosa and thecal cells of human ovarian follicles: stimulation by follicle-stimulating hormone. J Clin Endocrinol Metab. 1978;47:263-7.

97. Bosch Aparicio E, Alama P, Romero J, Mari M, Labarta E. Follicular steroidogenesis in GnRH antagonist ovarian stimulation cycles with rFSH vs. hp-HMG. A randomized controlled trial. Poster presented at the European Society of Human Reproduction and Embryology, Vienna, Austria, 23-16 June 2019.

98. de Ziegler D, Pirtea P, Andersen CY, Ayoubi JM. Role of gonadotropin-releasing hormone agonists, human chorionic gonadotropin (hCG), progesterone, and estrogen in luteal phase support after hCG triggering, and when in pregnancy hormonal support can be stopped. Fertil Steril. 2018;109:749-55.

99. de Ziegler D, Fanchin R. Endometrial receptivity in controlled ovarian hyperstimulation (COH): the hormonal factor. Ann N Y Acad Sci. 1994;734:209-20.

100. Sebag-Peyrelevade S, El Hachem H, Gallot V, Genro VK, Fanchin R. The influence of exogenous $\mathrm{LH} / \mathrm{hCG}$ activity on serum progesterone levels on the day of hCG administration in in vitro fertilization. J Gynecol Obstet Biol Reprod (Paris). 2015;44:524-31.

101. Lawrenz B, Labarta E, Fatemi H, Bosch E. Premature progesterone elevation: targets and rescue strategies. Fertil Steril. 2018;109:577-82.

102. Sunkara SK, Rittenberg V, Raine-Fenning N, Bhattacharya S, Zamora J, Coomarasamy A. Association between the number of eggs and live birth in IVF treatment: an analysis of 400135 treatment cycles. Hum Reprod. 2011;26:1768-74.

103. Orvieto R. HMG versus recombinant FSH plus recombinant $L H$ in ovarian stimulation for IVF: does the source of LH preparation matter? Reprod BioMed Online. 2019;39:1001-6.

104. Pacchiarotti A, Sbracia M, Frega A, Selman H, Rinaldi L, Pacchiarotti A. Urinary hMG (Meropur) versus recombinant FSH plus recombinant LH (Pergoveris) in IVF: a multicenter, prospective, randomized controlled trial. Fertil Steril. 2010;94:2467-9.

105. Ziebe S, Lundin K, Janssens R, Helmgaard L, Arce JC. Influence of ovarian stimulation with $\mathrm{HP}$-hMG or recombinant FSH on embryo quality parameters in patients undergoing IVF. Hum Reprod. 2007;22:2404-13.

106. Arce JC, Andersen AN, Fernandez-Sanchez M, Visnova H, Bosch E, GarciaVelasco JA, et al. Ovarian response to recombinant human folliclestimulating hormone: a randomized, antimullerian hormone-stratified, doseresponse trial in women undergoing in vitro fertilization/intracytoplasmic sperm injection. Fertil Steril. 2014;102:1633-40.e5.

107. Arce JC, Smitz J. Exogenous hCG activity, but not endogenous LH activity, is positively associated with live birth rates in anovulatory infertility. Hum Fertil. 2011;14:192-9.

108. Arce JC, La Marca A, Mirner Klein B, Nyboe Andersen A, Fleming R. Antimullerian hormone in gonadotropin releasing-hormone antagonist cycles: prediction of ovarian response and cumulative treatment outcome in good-prognosis patients. Fertil Steril. 2013;99:1644-53.

109. Coomarasamy A, Afnan M, Cheema D, van der Veen F, Bossuyt PM, van Wely M. Urinary hMG versus recombinant FSH for controlled ovarian hyperstimulation following an agonist long down-regulation protocol in IVF or ICSI treatment: a systematic review and meta-analysis. Hum Reprod. 2008;23:310-5.

110. Al-Inany HG, Abou-Setta AM, Aboulghar MA, Mansour RT, Serour GI. Efficacy and safety of human menopausal gonadotrophins versus recombinant FSH: a meta-analysis. Reprod BioMed Online. 2008;16:81-8.

111. van Wely M, Kwan I, Burt AL, Thomas J, Vail A, Van der Veen F, et al. Recombinant versus urinary gonadotrophin for ovarian stimulation in assisted reproductive technology cycles. Cochrane Database Syst Rev. 2011;2:CD005354.

\section{Publisher's Note}

Springer Nature remains neutral with regard to jurisdictional claims in published maps and institutional affiliations.

\section{Ready to submit your research? Choose BMC and benefit from:}

- fast, convenient online submission

- thorough peer review by experienced researchers in your field

- rapid publication on acceptance

- support for research data, including large and complex data types

- gold Open Access which fosters wider collaboration and increased citations

- maximum visibility for your research: over $100 \mathrm{M}$ website views per year

At $\mathrm{BMC}$, research is always in progress.

Learn more biomedcentral.com/submissions 